Civil Engineering

Volume 171 Issue CE5

Using stored snow as cooling at Oslo Airport, Norway

Moe

ice | proceedings
Proceedings of the Institution of Civil Engineers Civil Engineering 171 May 2018 Issue CE5 Pages 11-16 https://doi.org/10.1680/jcien.17.00041 Paper 1700041

Received 29/09/2017 Accepted 03/01/2018

Published online 23/02/2018

Keywords: airports; energy conservation; renewable energy

ICE Publishing: All rights reserved i

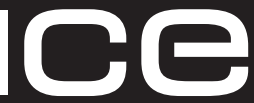

Institution of Civil Engineers

publishing

\title{
Using stored snow as cooling at Oslo airport, Norway
}

Jesper Mæx Moe BEng, MSc

Project Engineer, HVAC Department, COWI A/S, Oslo, Norway

(corresponding author: jmme@cowi.com)

A state-of-the-art snow cooling system was installed at Oslo airport in Norway in 2016 to reduce the energy costs of its new, bigger terminal building. Based on experiences of pioneering projects in Sweden and Japan, the environmentally friendly system is designed to reduce the summer cooling load by up to $5 \mathrm{MW}$. This paper describes the design and construction of the innovative snow cooling system and reports on its first 2 years of operation. In 2017 the system saved $375 \mathrm{MWh}$ compared to conventional cooling systems and further improvements are expected over the next 2 years.

\section{Introduction}

Norway's Oslo airport, in Gardermoen, opened in 1998, with a design capacity of 17 million passengers a year. Over 21 million passengers used the airport in 2011 , leading to the construction of a larger terminal between 2013 and 2017 (Figure 1). This increased the building floor area from $148000 \mathrm{~m}^{2}$ to $265000 \mathrm{~m}^{2}$ and raised passenger capacity to 28 million (Avinor, 2017).

Expansion also meant an increase in the need for heating and cooling at the airport. The airport has a private district heating and cooling grid, which serves large parts of the building complex with thermal energy. The grid is supplied from a thermal energy centre with heat pumps as the primary source.

Before expansion, the airport's cooling demand of $8 \mathrm{MW}$ was met by $6 \mathrm{MW}$ cooling effect heat pumps at the energy centre plus approximately $2 \mathrm{MW}$ of free cooling based on energy storage wells. Following expansion, cooling demand was calculated to increase to $19 \mathrm{MW}$ according to an unpublished COWI report. This has been covered by a new $4 \mathrm{MW}$ cooling-effect heat pump and a new $5 \mathrm{MW}$ snow cooling plant. An additional $5 \mathrm{MW}$ heat pump was also installed to meet the increase in heating demand to $35 \mathrm{MW}$.
Conventional cooling machinery is normally operated by electricity, increasing the need for energy and requiring that the energy flow is in balance, achieved by removing the excess heat produced by the cooling plant. The airport uses energy storage in groundwater wells, a dry cooler park, consumption of heat in the heating system and heat loss in the pipe network to achieve balance in the energy system by disposing of unwanted heat. A less energy-intensive cooling method is free cooling, in which cooling is produced without the use of anything except pump energy, by harnessing the heat exchanged between fluids with different temperatures.

Snow cooling stores snow and ice from the runway in the winter and uses the water from the melting snow for cooling in the summer by exploiting the characteristics of snow's thermal energy potential (Figure 2). This technique has the potential to be used in most temperate climate zones in the world, but Oslo airport's geographical location has climatic conditions that are close to ideal for such a system.

Energy design conditions were as follows (YR, 2017)

- latitude: $60 \cdot 1^{\circ}$ (about $40 \mathrm{~km}$ north of Oslo)

- average annual outdoor temperature: $5^{\circ} \mathrm{C}$

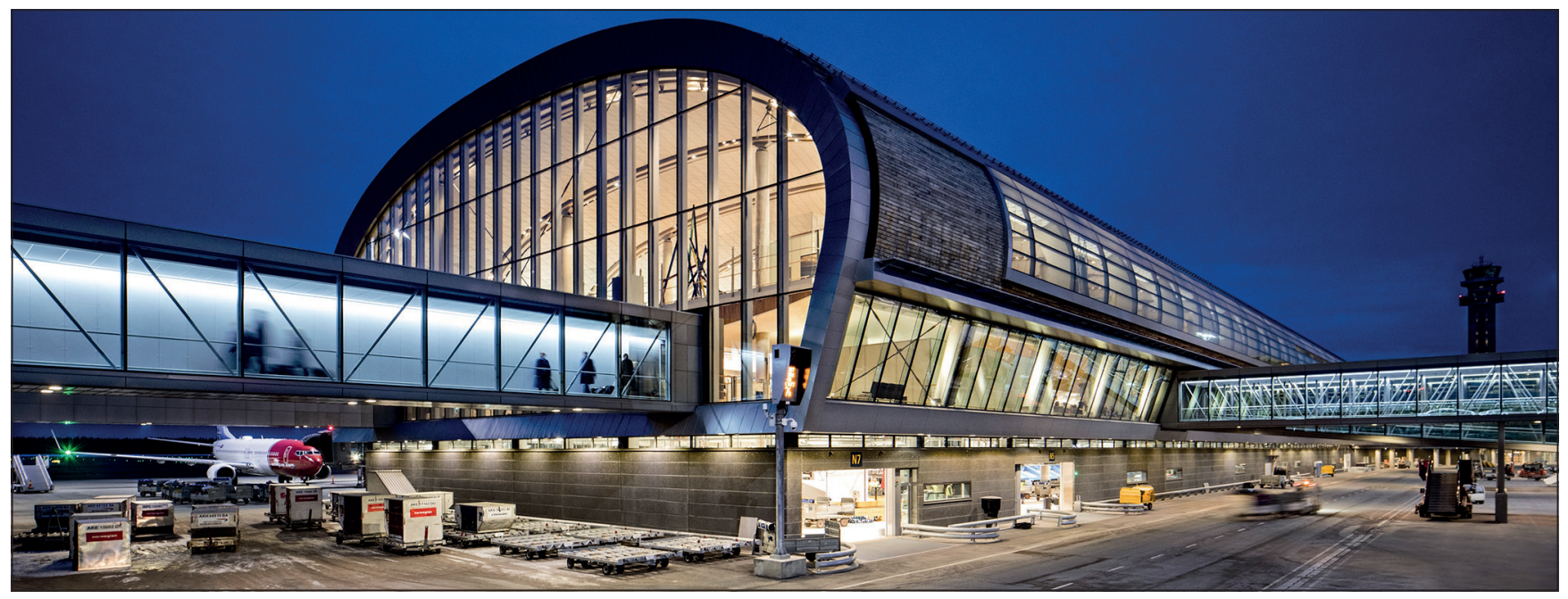

Figure 1. Opened in 2017, the new terminal at Oslo airport more than doubled summer cooling demand (Nordic Office of Architecture/ Ivan Brodey) 
- design outdoor temperature, winter: $-20^{\circ} \mathrm{C}$

- design outdoor conditions, summer: $27^{\circ} \mathrm{C}, 50 \%$ relative humidity

- design indoor temperature: $26^{\circ} \mathrm{C}$

- days with average outdoor temperature below $0^{\circ} \mathrm{C}$ : approximately 100 .

Another aspect that made using snow cooling attractive was that the airport already had one of the world's most advanced snow-clearing systems and needed to dispose of snow from the runways and taxiways in the winter. The main inspiration for the snow cooling plant came from Sundsvall Hospital in Sweden, where a snow cooling system has been used since 2000 with good results. There is also a similar plant at Hokkaido airport in Japan that has been operating since 2010 (Skogsberg, 2005; Nordell and Skogsberg, 2007).

\section{Seasonal storage of snow and using snow as an energy source}

Seasonal storage is done by saving the snow from the winter until the summer when cooling is required. The snow can be stored indoors, on the ground, in the ground or underground. To be able to exploit the potential for such systems to the maximum, the following criteria should be fulfilled

- large storage area available

- snow-clearing equipment available for storing and processing snow

- water and snow cannon available in combination with low average daily temperatures (optional).

Examples of locations where snow cooling systems can be a contributor to sustainable energy systems include snow mounds near places with high cooling needs: airports, hospitals, data centres, or industrial plant.

At Oslo airport the snow is stored in the ground and thermally insulated with wood chips. The cooling plant is designed for a maximum water volume of $200 \mathrm{l} / \mathrm{s}$ and with a conservative estimate of temperature difference in and out of the exchanger of $6 \mathrm{~K}$, equivalent to $5 \mathrm{MW}$. The energy delivered by the system is given by Equation 1.

1. $W=q_{\mathrm{v}} \times C \times \Delta T \times h$

where $W$ is delivered energy (MWh), $C$ is capacity/energy specific $(\mathrm{kJ} /(\mathrm{kg} \mathrm{K})), q_{\mathrm{v}}$ is mass flow $(\mathrm{kg} / \mathrm{s}), \Delta T$ is temperature difference $(\mathrm{K})$ and $h$ is time (h).

Snow cooling relies mainly on the latent melting heat of ice, the energy released by the phase change between ice and water. The constant melt temperature of ice at $0^{\circ} \mathrm{C}(273 \mathrm{~K})$ is a unique quality that makes the potential cooling effect of a snow cooling system virtually unlimited. Because the cold carrier is circulated through the snow at the same speed it is transported to the object being cooled, it is possible to achieve virtually limitless cooling effect simply by adjusting pump capacity. The system's high capacity makes it ideal for peak load coverage.

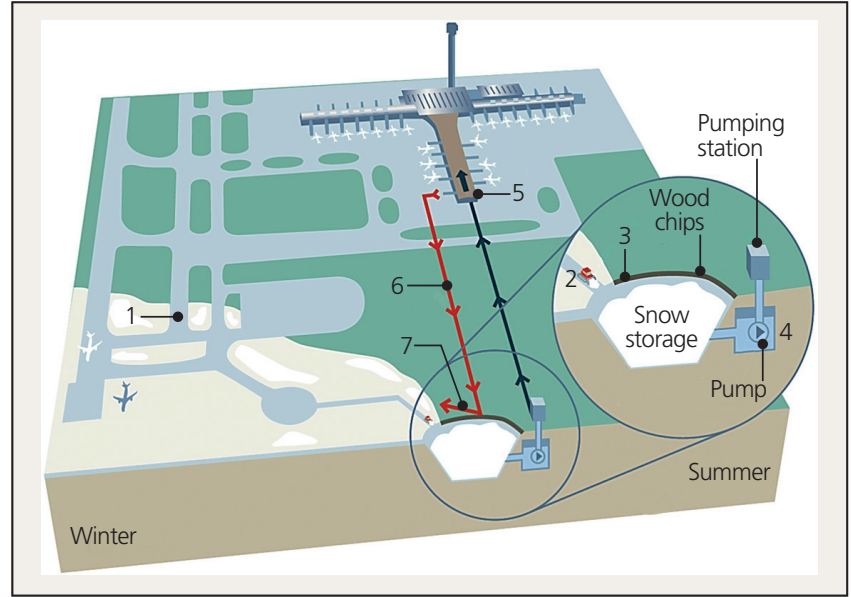

Figure 2. Snow cooling plant operation: 1. Snow collected from the whole airport area. 2. Snow deposited in snow storage. 3. During spring, snow covered by wood chips. 4. During summer snow melts and meltwater filtered and pumped to terminal. 5. Heat exchanger transfers cold water to airport central cooling system. 6 . Return water transferred to snow storage to keep melt process going. 7. Excess water spread over terrain (or infiltrated to ground) (COWI/Regina Fraimanaite)

The energy required to melt $1 \mathrm{~kg}$ of ice to water is $333 \cdot 55 \mathrm{~kJ} / \mathrm{kg}$ or $0.0926 \mathrm{kWh} / \mathrm{kg}$ under the assumption that the ice has the maximum attainable density of solid ice with hexagonal structure, which is $920 \mathrm{~kg} / \mathrm{m}^{3}$. Not all snow in a snow storage will be compressed to ice, meaning that density will be between 650 and $735 \mathrm{~kg} / \mathrm{m}^{3}$, which corresponds to $60-68 \mathrm{kWh} / \mathrm{m}^{3}$ of snow (Nordell, 2015). The stored energy of snow is given by Equation 2.

2. $W=V \times W=V \times \rho \times L$

where $W$ is stored energy (kWh), $V$ is volume $\left(\mathrm{m}^{3}\right), \rho$ is density $\left(\mathrm{kg} / \mathrm{m}^{3}\right)$ and $L$ is enthalpy of fusion $(\mathrm{kWh} / \mathrm{kg})$.

Because the purpose of snow storage is to store the ice collected during the winter until there is a cooling requirement in the summer, the plant has to be insulated. This is done at Oslo airport by adding a $20 \mathrm{~cm}$ thick layer of wood chips when the average temperature exceeds $0^{\circ} \mathrm{C}$ to reduce the melting process, so that it will be possible to use the snow storage throughout the summer season.

Most of the meltwater drains down through the snow and into the pool, but because of evaporation and capillary effect, some of it will also move upward through the wood chips. Evaporation from the chips helps cool down the snow, and their low thermal conductivity $(0 \cdot 08-0 \cdot 32 \mathrm{~W} / \mathrm{mK})$ means that chips are an excellent insulation material for snow (Skogsberg, 2005; unpublished COWI document with test of insulation for snow). Covering the snow storage is accomplished by using a snow blower that spreads the chips evenly over the snow. The problem with using wood chips as an insulation material is that the decomposition process uses oxygen from the water, changing the chemical composition and creating water with a low oxygen content. 
Snow melting in a cooling plant can be divided into forced and natural melting. Forced melting is the result of circulation of the energy carrier, which in this case is the re-infiltration of the water returned from the heat exchanger. Natural melting is due to surface melting, ground melting and rain melting, which in such a system are losses. The main component in natural melting is surface melting as a result of the air temperature (Nordell and Skogsberg, 2007). The monthly melt loss due to air temperature is given by Equation 3.

$$
\text { 3. } Q_{\text {air per month }}=A \times \lambda_{\text {wood chips }} \times \frac{\Delta T}{\Delta Z_{\text {wood chips }}} \times h
$$

where $Q_{\text {air }}$ is melt loss due to air temperature per month (MWh), $A$ is area $\left(\mathrm{m}^{2}\right), \lambda_{\text {wood chips }}$ is thermal conductivity of wood chips $(\mathrm{W} / \mathrm{mK}), \Delta T$ is temperature difference $(\mathrm{K}), \Delta Z_{\text {wood chips }}$ is thickness of wood chips (m) and $h$ is hours per month.

The use of snow cannons can be a good supplement or backup solution for filling up the snow storage in winters with poor snowfall but low outdoor temperatures. This is because the drain water that has to be removed has to pass the snow storage. Therefore it is possible to produce artificial snow with only the costs of the energy used for the snow cannon. Another positive aspect of snow production is that it is completely free of sand, and thus has a very high albedo that will reflect sunlight better if exposed in instances when wood chips slide off the snow pile. The use of snow cannons in winters with poor snow fall could be an excellent way to fill up the snow storage.

In the current climate norm based on climate data from 19611990 (the new climate norm will be 1991-2020), there is an average of 141 days of sub-zero temperatures at Gardermoen. However, temperature data from recent years show this is now approximately just 100 days a year. As a result of climate change, the trend might continue and lead to problems obtaining enough snow to fill up the snow storage (YR, 2017).

Snow at Oslo airport is divided into two categories, pure and impure. Impure snow contains aircraft and runway de-icing fluids, and is collected in pools where the meltwater is gradually released to the municipal sewage treatment plant to avoid pollution of groundwater. Pure snow, which can contain sand, is deposited in the snow storage. What is left at the end of the season will be wood chips, water and sand.

The water can be drained and spread on the ground, while wood chips and sand have to be removed mechanically. By separating sand and chips and through a cleaning process, chips can be used for up to four seasons as long as there are sufficient storage facilities, before their insulation properties are reduced due to decomposition.

\section{Description of the plant}

The snow cooling plant at Oslo is dimensioned for a thermal peak load of $5 \mathrm{MW}$, mainly for the new building, and with an energy potential of $3 \mathrm{GWh}$ in the course of a season. This accounts for approximately $12 \%$ of the energy capacity and $25 \%$ of the power capacity for cooling at the airport. This complements the effect-duration curve for the airport extremely well as there are relatively few days with high cooling requirement.
The main elements of the plant are a snow storage pit, a pumping station, a heat exchanger and a stone reservoir (Figure 3 ). The waterproof asphalted pit has an area of $10000 \mathrm{~m}^{2}(84 \mathrm{~m} \times$ $120 \mathrm{~m}$ ) and is $4.5 \mathrm{~m}$ deep. The pool consists of a reinforced layer, supporting layer and three layers of asphalt, with a membrane between the top two layers, making it possible for heavy vehicles to drive down into the pool.

The steepest possible side slopes should be used to increase volume and reduce loss due to natural melting. However, the use of asphalt puts limitations on the slope angle. Furthermore, to allow access for cleaning vehicles at the end of each season, the pool was constructed with a 1:4 inclination on the long north and south sides, 1:6 on the east side and a retaining wall on the west side. The incline ratios were optimised in terms of construction and access compared to the requirement for the greatest possible storage volume. This corresponds to a storage volume of about $30000 \mathrm{~m}^{3}$ below ground, but the total storage volume is estimated at $90000 \mathrm{~m}^{3}$ by filling up to $9 \mathrm{~m}$ above ground.

To reduce the potential risk of leakage from the snow storage, the number of penetrations in the membrane was kept to a minimum and grouped in separate zones. In total there are 24 penetrations for re-infiltration of water, grouped into four zones. Pipes for distribution to extraction points were laid above membrane level wherever possible.

The pit bottom has a $0.5 \%$ slope down towards the inlets. The highest water level in the pit from its lowest point at the inlet to the pump sump is $4.35 \mathrm{~m}$, which is $0.6 \mathrm{~m}$ lower than the pit edge. The outlet for the re-infiltrated water is $2.88 \mathrm{~m}$ above the lowest point of the pit. The bottom of the thermal snow storage consists of a $450 \mathrm{~mm}$ thick reinforcement layer, a $100 \mathrm{~mm}$ thick supporting layer, a $50 \mathrm{~mm}$ binding layer and a $50 \mathrm{~mm}$ surface layer with a slip membrane between.

The inclined sides have a slightly different construction, consisting of a $390 \mathrm{~mm}$ reinforcement layer, a $100 \mathrm{~mm}$ supporting layer, two $50 \mathrm{~mm}$ supporting layers and a $50 \mathrm{~mm}$ surface layer on the top. The west-end retaining wall is made from reinforced concrete. It is $84 \mathrm{~m}$ long, $7 \mathrm{~m}$ high from the bottom, $0.5 \mathrm{~m}$ thick up to ground level and $200 \mathrm{~mm}$ thick for the upper $1.4 \mathrm{~m}$.

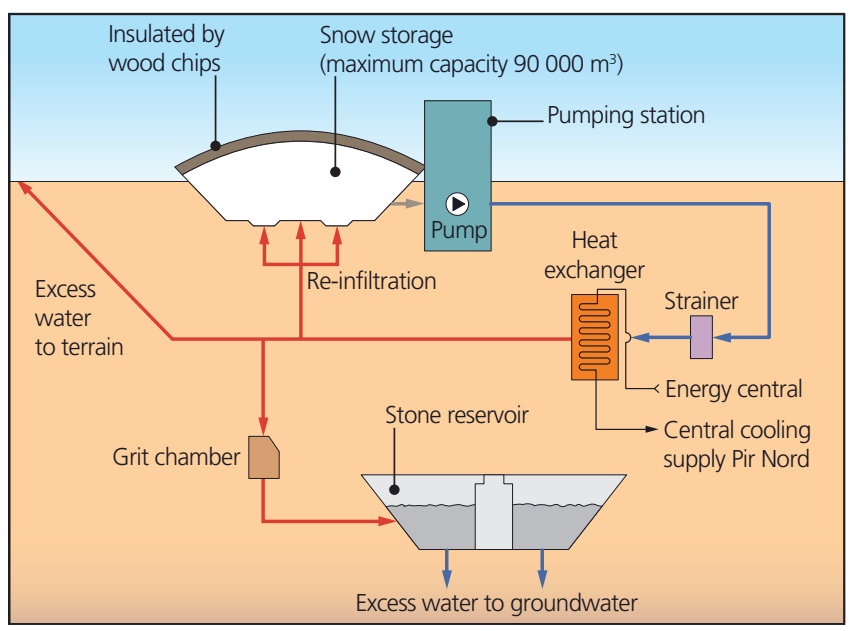

Figure 3. Components of snow cooling plant (COWI/Regina Fraimanaite) 
The pumping station is a three-storey building integrated into the end wall (Figure 4). The superstructure has side walls of reinforced concrete that are $350 \mathrm{~mm}$ thick, with $100 \mathrm{~mm}$ insulation on the inside, $70 \mathrm{~mm}$ Leca block covered with $10 \mathrm{~mm}$ render. Between the concrete of the superstructure and the retaining wall is an additional $150 \mathrm{~mm}$ of insulation on the outside against the snow storage. The upper floor deck is $300 \mathrm{~mm}$ of concrete with a $100 \mathrm{~mm}$ vapour barrier, $350 \mathrm{~mm}$ insulation with a galvanised steel plate on top.

The superstructure stands above ground level, with the switchboard, pressure tank and a container to catch spill from the sieve conveyor. The two basement floors are divided by a floor grate and most of the important installations such as the circulation pumps, pump sump, drain sump, overflow sump and belt sieve are found in the sub-basement.

The snow storage pit is located $1 \mathrm{~km}$ north of the new terminal and is filled during winter using snow blowers (Figure 5). During summer, meltwater from the pit is circulated using two $50 \mathrm{~kW}$ pumps in a non-insulated $400 \mathrm{~mm}$ diameter fibreglass pipe laid below the frost level under transverse taxiways. Meltwater can be extracted from three different inlets on the western side of the pit where the pumping station is located. Before the meltwater reaches the pumps, it passes through a belt sieve to avoid foreign objects, such as wood chips, in the pumps and pipe system.

The meltwater is transported to a central heat exchanger north of the new terminal, where it is first fine-filtered in a rotating automatic filter before being exchanged with the return water in the district cooling circuit to cool it. The heated meltwater is then returned to the snow pit to keep the melting process going (Figure 6). Four different valves around the snow storage pit provide re-infiltration of return water at different points in the pit. Infiltration is performed to ensure that the water is kept as long as possible in the snow storage to cool it down, preferably to $0-2^{\circ} \mathrm{C}$.
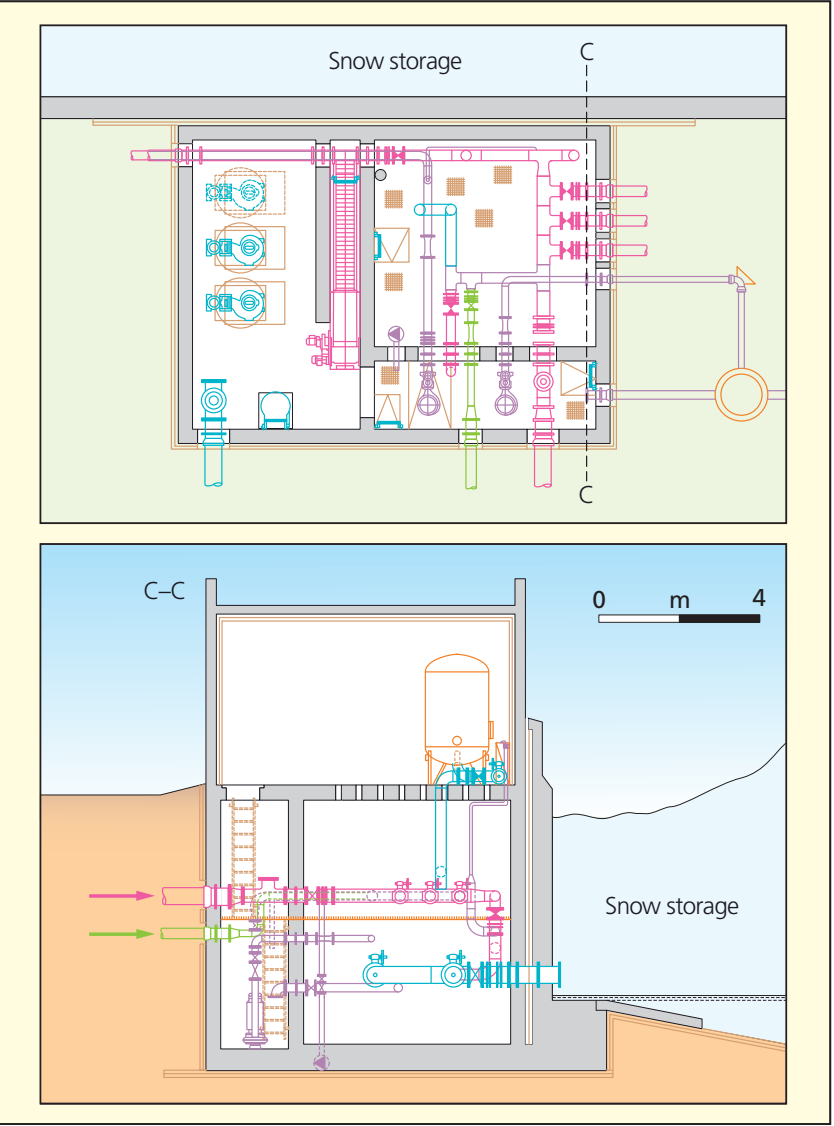

Figure 4. Plan view of pumping station basement (top) and cross-section (Team T)

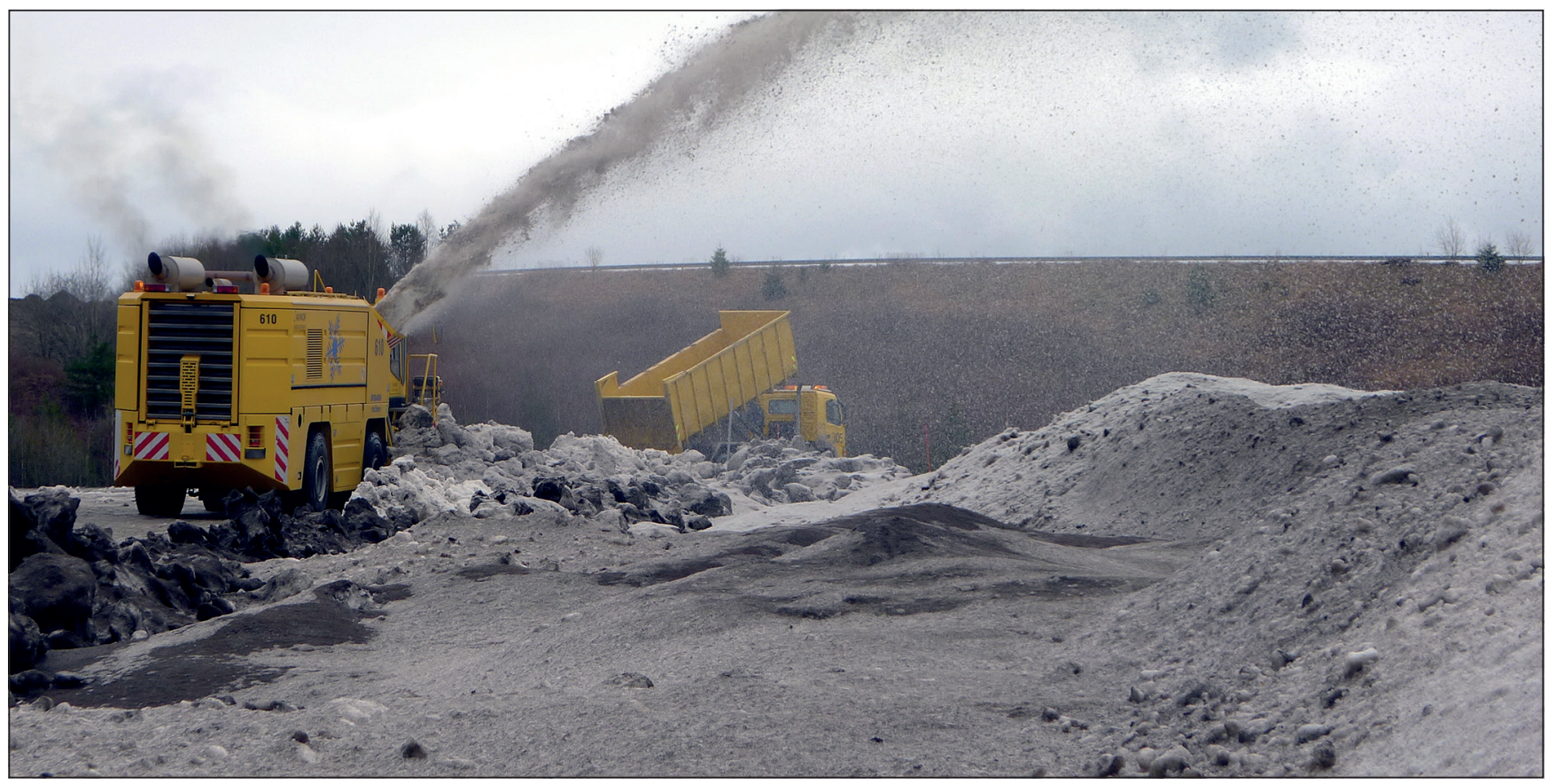

Figure 5. The snow storage pit is filled in winter using snow blowers (Avinor/Halvard Felde) 


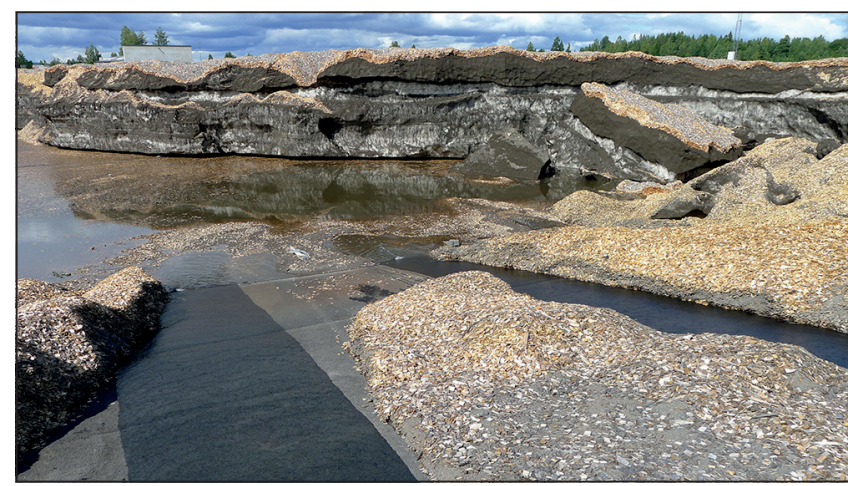

Figure 6. Warmed meltwater is returned to the snow storage pit during summer (Avinor/Halvard Felde)

To prevent tunnels and channels in the snow and ice that could potentially reduce the contact surface and heat transfer between snow and water, opening the inlet and re-infiltration valves has to be performed in sequence.

A $50 \mathrm{~kW}$ pump for spreading the water on the ground and an $11 \mathrm{~kW}$ pump for draining it to a stone reservoir ensures that all surplus water from snow melting is pumped out.

To have time to wash and clean the pit for the next season, all the snow in the snow storage must be used. The melt phase with priority cooling means that the cooling effect value is set low so that snow cooling will cover most of the cooling requirements until the storage is empty. Sediment and chips can then be cleaned from the pit and preparation done for the next season (Figure 7). Washing at the end of each season is important to avoid algae formation in the heat exchanger, causing increased pressure drop, reduced capacity and heat transfer properties.

\section{Results}

Before the summer of 2016, approximately $30000 \mathrm{~m}^{3}$ of snow was stored, with an estimated density of $735 \mathrm{~kg} / \mathrm{m}^{3}$, equivalent to stored cooling energy of about $2000 \mathrm{MWh}$. In the subsequent first year test operation, $800 \mathrm{MWh}$ was produced, meaning a loss of $60 \%$ (Figure 8 ). Natural melting was the main cause of the loss and accounted for $45 \%$ of the energy loss of $1200 \mathrm{MWh}$. The seasonal coefficient of performance for the first summer, including pumping power for the circulation pumps and drainage of excess water but excluding energy for materials, wood chips and transport, was $18 \cdot 2$, considerably higher than what would be expected from conventional cooling machines (normally around 3).

A total of $45000 \mathrm{~m}^{3}$ of snow with the same estimated density as the year before was deposited in the winter of 2016/2017, which would indicate around $3000 \mathrm{MWh}$ of cooling energy stored in the snow. Delivered cooling energy for 2017 was $1350 \mathrm{MWh}$, suggesting an energy loss of $55 \%$, which is a small improvement from the first year of test operation. Seasonal coefficient of performance was 17.9 and $18 \cdot 7$, respectively, and depending on whether pump power for the snow cannon is included or not. With $1350 \mathrm{MWh}$ of cooling delivered, using $75 \mathrm{MWh}$ for operating the pumps in the system, the energy savings compared to a

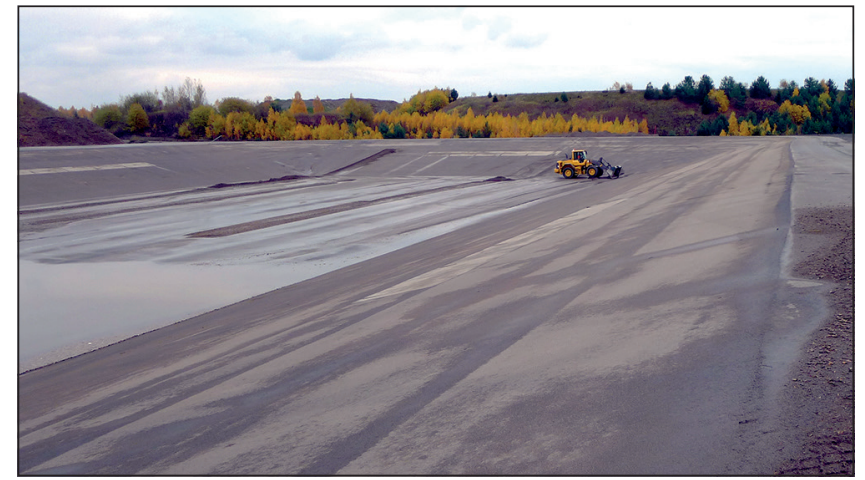

Figure 7. The snow storage pit needs cleaning of sand and wood chip insulation after each summer (Avinor/Halvard Felde)

conventional cooling machine with a coefficient of performance factor of 3 were $375 \mathrm{MWh}$ (Figure 9).

The highest effect delivery from the first two seasons was $3 \cdot 7 \mathrm{MW}$ in 2016 and $4.5 \mathrm{MW}$ in 2017 , when the plant was in normal operation, but a test run early in the summer of 2016 registered a cooling effect of $5.5 \mathrm{MW}$. This shows that the plant has the potential to deliver a higher cooling effect than the $5 \mathrm{MW}$ it is designed to cover.

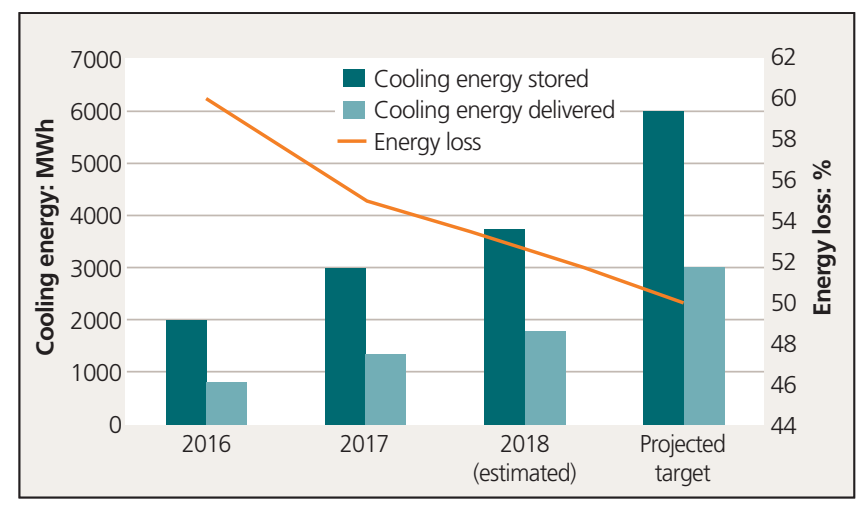

Figure 8. Snow cooling energy delivered and energy loss per year

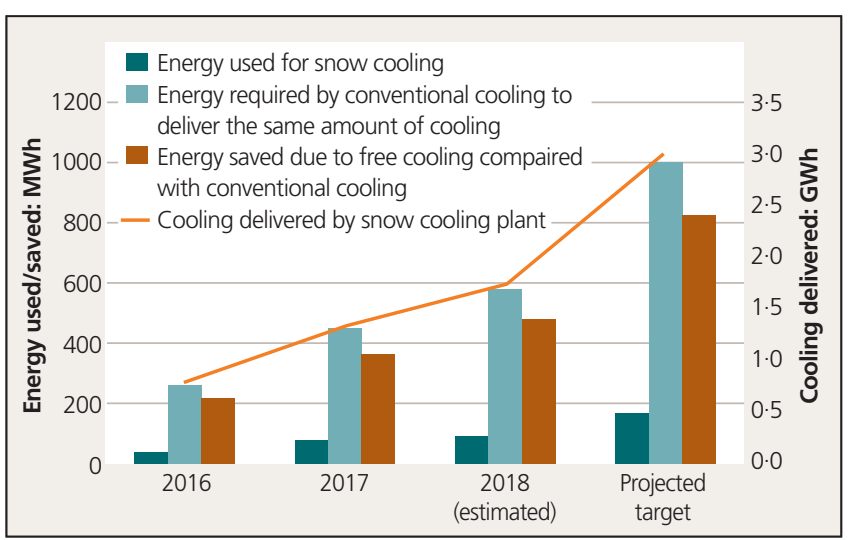

Figure 9. Energy saved due to snow cooling plant per year 
An attempt was made between 10 and 17 February 2017 to use the snow cannon to produce snow directly for the snow storage. The snow cannon had an estimated average effect of $17 \cdot 5 \mathrm{~kW}$ and an average amount of added water of $18 \mathrm{~m}^{3} / \mathrm{h}$. The temperature during the whole experimental period was below $0^{\circ} \mathrm{C}$, allowing snow to be produced continuously. Pump power needed for the entire period was $3.4 \mathrm{MWh}$, while the total accumulation of snow added to the snow storage was $4700 \mathrm{~m}^{3}$, which with an estimated density of $735 \mathrm{~kg} / \mathrm{m}^{3}$ supplied $320 \mathrm{MWh}$ of stored cooling energy. Even with a loss of $50 \%$, the coefficient of performance for producing snow for cooling will be close to 50 .

To fill up the snow storage from $45000 \mathrm{~m}^{3}$ to $90000 \mathrm{~m}^{3}$ with a snow density of $735 \mathrm{~kg} / \mathrm{m}^{3}$, two snow cannons equivalent to that mentioned above could be used for 38 days, using total energy of $63 \mathrm{MWh}$. This would have doubled the amount of stored energy in the snow storage to $6000 \mathrm{MWh}$ needed to supply the plant's energy potential of $3000 \mathrm{MWh}$.

\section{Discussion}

The most important factor associated with running the plant will be to make sure that the procedures are in place to keep making the snow storage pit as full as possible during the deposit phase. Each extra $1 \mathrm{~m}$ of snow added in the pit will increase the stored cooling energy by about $700 \mathrm{MWh}$, which shows the importance of this priority.

Another positive consequence of depositing snow with the highest level above the ground will be that the volume will increase much more than surface area. This will make the energy loss due to natural melting relatively smaller compared to the stored cooling energy in the snow pile. The fact that the snow storage was only filled up with $45000 \mathrm{~m}^{3}$ before the summer of 2017 can have several causes. Rainfall in the winter of 2016/2017 was $234 \mathrm{~mm}$, which is considerably lower than $415 \mathrm{~mm}$ falling in the winter of a normal year. In addition, snow clearance crew operating procedures may not have been changed sufficiently to focus on depositing snow in the storage.

The cooling energy supplied has increased by $70 \%$ from the test season to the first year of normal operation. There is still some way to go up to the plant's energy potential of $3 \mathrm{GWh}$. Given the amount of stored energy the plant supplied, it is working relatively satisfactorily. The loss of 55\% in 2017 is 5\% higher than planned, but has been better compared to the first season. In other words, the amount of snow in the storage is the decisive factor in reaching the plant's potential.

The cooling effect of the plant has been lower than planned in the first two seasons. The reasons can mainly be ascribed to these summers not having long periods of high outdoor temperatures or high humidity. This has meant that the cooling needs of the terminal were low, and gave low return temperatures in the district cooling grid. Low return temperatures in the district cooling grid make it difficult to realise the effect potential from snow cooling. The average temperature in the return district cooling circuit when snow cooling was in operation was $14 \cdot 2^{\circ} \mathrm{C}$, which is $2 \cdot 8^{\circ} \mathrm{C}$ colder than the designed return temperature.

As a result of a high investment cost and the need for a large storage area, the spreading potential for such plants will typically be greatest in the event of large-scale expansion or new construction.
Snowy cities that have environmental problems related to the runoff of polluted water from their snow dumps can take advantage of local cooling requirements during the summer to deliver cooling by means of a high energy efficiency district cooling grid, and collect and treat the pollution.

\section{Conclusions}

After two seasons of running the Oslo airport snow cooling plant, it can be said that the plant is working satisfactorily in terms of energy delivered compared with energy stored, but there are several elements that can be improved. Most of these will be linked to implementation of operating procedures to ensure the snow storage is kept filled up for the snow clearance personnel, as well as experiences and management of the snow pile for operating personnel.

The plant helps to profile the airport as an innovative facility using available resources that would otherwise go to waste, and that utilises machinery and manpower at the airport used for dealing with snow.

The concept could be applicable to multiple locations that have large spaces available and where there are large cooling requirements in the local area. Snowy cities with snow dumps nearby can also increase their renewable production of cooling while controlling run-off of polluted water from their dumps so that it can be treated correctly.

\section{Acknowledgements}

The author would like to acknowledge senior engineer Frode Fjeldstad at COWI, project manager for heating, ventilation and air conditioning operations at Oslo airport, for his contribution and assistance with this paper.

\section{References}

Avinor (2017) Traffic Statistics. See https://avinor.no: AVINOR. https://avinor. no/en/corporate/about-us/statistics/archive (accessed 07/03/2017).

Nordell B (2015) Using ice and snow in thermal energy storage systems. In Advances in Thermal Energy Storage Systems: Methods and Applications (Cabeza LF (ed.)). Woodhead Publishing, Cambridge, UK.

Nordell B and Skogsberg K (2007) The Sundsvall snow storage - six years of operation. In Thermal Energy Storage for Sustainable Energy Consumption (Paksoy HÖ (ed.)). Springer, Dordrecht, the Netherlands, pp. 349-366.

Skogsberg K (2005) Seasonal snow storage for space and process cooling. Doctoral thesis, Luleå University of Technology, Luleå, Sweden.

YR (2017) Værstatistikk for Gardermoen. See http://www.yr.no/sted/Norge/ Akershus/Ullensaker/Oslo_lufthavn_Gardermoen/statistikk.html (accessed 01/04/2017) (in Norwegian).

\section{How can you contribute?}

If you would like to comment on this paper, please email up to 200 words to the editor at journals@ice.org.uk.

If you would like to write a paper of 2000 to 3500 words about your own experience in this or any related area of civil engineering, the editor will be happy to provide any help or advice you need. 